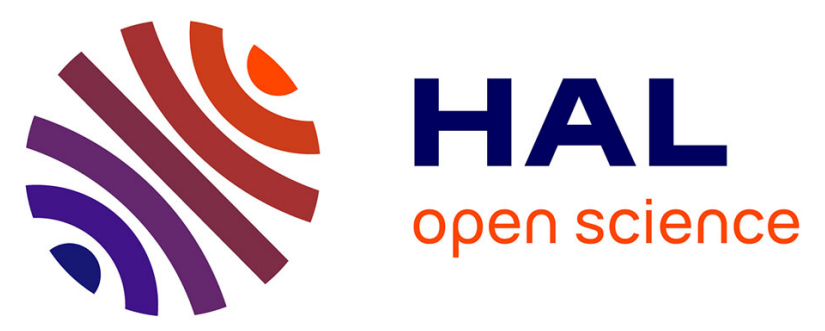

\title{
Applicability of Model Updating Method to Different Detection Indexes of Cold Fresh Pork
}

Shanmei Liu, Hui Peng, Ruifang Zhai, Jun Luo

\section{To cite this version:}

Shanmei Liu, Hui Peng, Ruifang Zhai, Jun Luo. Applicability of Model Updating Method to Different Detection Indexes of Cold Fresh Pork. 10th International Conference on Computer and Computing Technologies in Agriculture (CCTA), Oct 2016, Dongying, China. pp.101-110, 10.1007/978-3-03006155-5_10. hal-02179960

\section{HAL Id: hal-02179960 https://hal.inria.fr/hal-02179960}

Submitted on 11 Jul 2019

HAL is a multi-disciplinary open access archive for the deposit and dissemination of scientific research documents, whether they are published or not. The documents may come from teaching and research institutions in France or abroad, or from public or private research centers.
L'archive ouverte pluridisciplinaire $\mathbf{H A L}$, est destinée au dépôt et à la diffusion de documents scientifiques de niveau recherche, publiés ou non, émanant des établissements d'enseignement et de recherche français ou étrangers, des laboratoires publics ou privés. 


\title{
Applicability of model updating method to different detection indexes of cold fresh pork
}

\author{
Shanmei Liu ${ }^{1}$, Hui Peng $\left.{ }^{1(}{ }^{\circledR}\right)$ Ruifang Zhai ${ }^{1}$, Jun Luo ${ }^{1}$ \\ ${ }^{1}$ College of Informatics, Huazhong Agricultural University, Wuhan Hubei,China \\ \{lsmei, moonbird, zhairuifang, luojun\}@mail.hzau.edu.cn
}

\begin{abstract}
Model updating method is used to maintain the hyperspectral models established to predict water content, $\mathrm{pH}$ value, and TVB-N content of cold fresh pork. After adding 11 slave variety samples to the calibration set of the master variety samples, the prediction results of the updated model of water content for the slave variety samples were $\mathrm{R}_{\mathrm{p}}{ }^{2}=0.8224$ and $\mathrm{RPD}=1.94$. After adding 45 slave variety samples, the prediction results of the updated model of $\mathrm{pH}$ value for the slave variety samples were $\mathrm{R}_{\mathrm{p}}{ }^{2}=0.6160$ and $\mathrm{RPD}=1.34$. After adding 9 slave variety samples, the results of the updated model of TVB-N content for the slave variety samples were $\mathrm{R}_{\mathrm{p}}{ }^{2}=0.9073$ and $\mathrm{RPD}=3.04$. The findings show that the model updating method can well maintain the TVB-N content model but shows poor maintenance ability for water content model, and it cannot be used to maintain the $\mathrm{pH}$ value model. Therefore, the applicability of the model updating method varies in different detection index models for cold fresh pork.
\end{abstract}

Keywords: model updating method, water content, $\mathrm{pH}$ value, TVB-N content

\section{Introduction}

Multivariate calibration models are of critical importance in analytical measurements when adopting spectroscopy technique for quantitative detection of the components of agriculture and livestock products. However, calibration models cannot be applied in all instances. The performance of multivariate calibration models can be affected by changes in instruments, samples, and surroundings, among others. To guarantee the effectiveness of multivariate calibration models, we should maintain them when their prediction performance drops [1,2]. Model updating is the most commonly used method for model maintenance $[3,4,5,6]$. It is usually used to address the issues that invalidate a model caused by changes in samples (such as the use of different varieties, the use of samples obtained from different places or at different times, and the use of samples stored under different conditions), environment for sample measurement (such as changes in temperature and humidity), and some other factors.

Most surveys have shown that the predictability of samples at different temperature, when using different instruments, and under some other situations improved when a model is maintained using the model updating method $[7,8,9,10$, $11,12,13,14,15,16]$. However, these surveys did not study the improvement degree for the new sample predictability and the influence degree for the prediction precision 
of original samples. To eliminate the effects of the difference in varieties on calibration models, we used the model updating method to maintain the calibration model of three indexes (water content, $\mathrm{pH}$, and TVB-N) of cold fresh pork in this study. The prediction performance of the TVB-N content model for predicting the master variety and the slave variety pork samples before and after using the model updating method was compared, and so done for $\mathrm{pH}$ value and water content models. Then we can ascertain the explicabilities of the model updating method in maintaining the models for different indexes of cold fresh pork.

\section{Materials and Methods}

\subsection{Materials}

The cold fresh pork samples used in our experiments were purchased from local supermarkets in Hongshan District, Wuhan City, Hubei province. To study the effects of different varieties, we selected the Enshi mountain pigs and the No.0 indigenous pigs as detection objects when determining the water content and $\mathrm{pH}$ value of cold fresh pork. The Enshi mountain pigs and the Jiajiakang pigs were used as detection objects when determining the TVB-N content of cold fresh pork. We prepared samples consisting of back tenderloin of 82 Enshi mountain pigs and 79 No.0 indigenous pigs for water content and $\mathrm{pH}$ value detection. We prepared samples consisting of back tenderloin of 96 Enshi mountain pigs and 96 Jiajiakang pigs to determine the TVB-N content.

\subsection{Acquisition of Spectral Data}

After preparing the experimental samples, we first adopted HyperSIS hyperspectral imaging system which was purchased from Beijing Zhuo-li-han-guang Instrument Co.Ltd to obtain the hyperspectral data of each pork sample. The ENVI4.7 software was subsequently used to extract spectral data from the hyperspetral data.

\subsection{Measurement of Physicochemical Reference Values}

Immediately after we collected the hyperspactral data of the pork samples, we conducted the experiments to determine the physicochemical reference value of all the samples.

The reference value for water content of cold fresh pork was measured using vacuum drying method, in accordance with the national standard of the People's Republic of China GB5009.3-2010 [17].

The reference value for $\mathrm{pH}$ value of cold fresh pork was measured using a $\mathrm{pH}$ meter in accordance with the standard of agriculture ministry of the People's Republic of China NY/T 821-2004 [18]. 
The reference value for TVB-N content of cold fresh pork was measured by microdiffusion method in accordance with the national standard of the People's Republic of China GB/T 5009.44-2003[19].

\subsection{Model Updating Method}

Model updating method used in this paper aimed to eliminate the influence of variety difference on the hyperspectral models of cold fresh pork. No.0 indigenous pigs and Enshi mountain pigs were selected as the master variety and slave variety, respectively, to predict the water content and $\mathrm{pH}$ value of cold fresh pork. In addition, Enshi mountain pigs and Jiajiakang pigs were chosen as the master variety and slave variety, respectively, to predict the TVB-N content of cold fresh pork. Firstly, the sample set of the master variety were divided into calibration set and test set, and the PLSR models for predicting the TVB-N content, $\mathrm{pH}$ value, water content were established with the calibration set of the master variety. Then a small amount of representative slave variety samples were selected and added to the calibration set of the master variety by using SPXY algorithm [20] to establish the updating models. The rest samples of the slave variety were used as test set to validate the results of model updating.

\subsection{Method to Evaluate the Updating Model}

The results of the updating model was evaluated according to the foundation of the model performance by using 5 parameters such as the cross validation coefficient of determination $\mathrm{R}_{\mathrm{cv}}{ }^{2}$, the root mean square error of cross validation (RMSECV), the prediction coefficient of determination $\mathrm{R}_{\mathrm{p}}{ }^{2}$, the root mean square error of prediction ( RMSEP), and residual prediction deviation (RPD).

The foundation of the model performance can be assessed as follows [21]: when $\mathrm{R}^{2}<=0.50\left(\mathrm{R}^{2}\right.$ stands for $\mathrm{R}_{\mathrm{cv}}{ }^{2}$ and $\left.\mathrm{R}_{\mathrm{p}}{ }^{2}\right)$ and $\mathrm{RPD}<=1.5$, the model established is not available. When $0.50<\mathrm{R}^{2}<=0.65$ and $1.5<\mathrm{RPD}<2.0$, the model established can identify the high or low value of the measurement. When $0.65<\mathrm{R}^{2}<0.81$ and $2.0<\mathrm{RPD}<=2.5$, the model can be used in approximate quantitative calculation. When $0.81<\mathrm{R}^{2}<=0.90$ and $2.5<\mathrm{RPD}<=3.0$, the model performance is good. When $\mathrm{R}^{2}>0.90$ and RPD $>3.0$, the model shows excellent performance. The larger the $\mathrm{R}^{2}$ and RPD, the smaller the RMSECV and RMSEP, the better the model performance will be.

\section{Results and Analysis}

\subsection{PLSR Model of Each Index of the Master Variety}

After eliminating 5 abnormal No.0 indigenous pork samples and 8 abnormal Enshi mountain pork samples found by using the Monte Carlo method [22], we obtained 74 normal No.0 indigenous pork samples and 74 normal Enshi mountain pork samples for predicting water content of cold fresh pork. The No.0 indigenous pork was selected as master variety and the Enshi mountain pork was selected as slave variety. 
By using CG algorithm [23], we divided the 74 master variety samples into calibration set and test set at 3:1 ratio. The calibration set was used to establish the PLSR model called the master variety PLSR model for predicting water content of cold fresh pork.

After eliminating 6 abnormal No.0 indigenous pork samples and 6 abnormal Enshi mountain pork samples found by using the Monte Carlo method, we obtained 73 normal No.0 indigenous pork samples and 76 normal Enshi mountain pork samples for predicting $\mathrm{pH}$ value of cold fresh pork. The No.0 indigenous pork and Enshi mountain pork were selected as the master and slave varieties, respectively. By using SPXY algorithm, we divided the 73 master variety samples into calibration set and test set at 3:1 ratio. The calibration set was used to establish the PLSR model for predicting $\mathrm{pH}$ value of cold fresh pork.

After eliminating 9 abnormal Enshi mountain pork samples and 6 abnormal Jiajiakang pork samples by using the Monte Carlo method, we obtained 87 normal Enshi mountain pork samples and 90 normal Jiajiakang pork samples for predicting TVB-N content of cold fresh pork. Enshi mountain pork and Jiajiakang pork were selected as the master and slave varieties, respectively. By using CG algorithm, we divided the 87 master variety samples into calibration set and test set at 3:1 ratio. The calibration set was used to establish the PLSR model for predicting TVB-N content of cold fresh pork.

Table 1 shows the performance parameters of the PLSR model of master variety pork for predicting water content, $\mathrm{pH}$ value, and TVB-N content.

Table 1. The performance parameters of the master variety PLSR model for predicting water content, $\mathrm{pH}$ value, and TVB-N content

\begin{tabular}{|c|c|c|c|c|c|c|c|c|c|}
\hline \multirow{2}{*}{$\begin{array}{l}\text { The master } \\
\text { variety PLSR } \\
\text { model }\end{array}$} & \multicolumn{3}{|c|}{ Cross validation results } & \multicolumn{3}{|c|}{$\begin{array}{l}\text { Prediction results of master } \\
\text { varieties }\end{array}$} & \multicolumn{3}{|c|}{$\begin{array}{c}\text { Prediction results of slave } \\
\text { varieties }\end{array}$} \\
\hline & $\mathrm{R}_{\mathrm{cv}}^{2}$ & RMSECV & RPD & $\mathrm{R}_{\mathrm{p}}{ }^{2}$ & RMSEP & RPD & $\mathrm{R}_{\mathrm{p}}^{2}$ & RMSEP & RPD \\
\hline Water content & 0.9593 & 0.2091 & 4.99 & 0.9301 & 0.2521 & 3.53 & 0.2678 & 1.0300 & 0.87 \\
\hline $\mathrm{pH}$ value & 0.8726 & 0.0817 & 2.80 & 0.7426 & 0.0710 & 2.02 & 0.3492 & 0.1509 & 0.86 \\
\hline TVB-N content & 0.9706 & 1.1324 & 5.88 & 0.9503 & 1.5190 & 4.25 & 0.6992 & 3.0513 & 1.58 \\
\hline
\end{tabular}

We can draw the following conclusions from Table 1.The prediction results of the master variety PLSR model for predicting water content of the master variety are $\mathrm{R}_{\mathrm{p}}{ }^{2}=0.9301>0.90$ and $\mathrm{RPD}=3.53>3.0$, and that for predicting water content of the slave variety are $R_{p}{ }^{2}=0.2687<0.50$ and $R P D=0.87<1.5$. The prediction results of the master variety PLSR model for predicting $\mathrm{pH}$ value of the master variety are $0.65<\mathrm{R}_{\mathrm{p}}{ }^{2}=0.7426<0.81$ and $2.0<\mathrm{RPD}=2.02<2.5$, and that for predicting $\mathrm{pH}$ value of the slave variety are $\mathrm{R}_{\mathrm{p}}{ }^{2}=0.3492<0.50$ and $\mathrm{RPD}=0.86<1.5$. The prediction results of the master variety PLSR model for predicting TVB-N content of the master variety are $R_{p}{ }^{2}=0.9503>0.90$ and $R P D=4.25>3.0$, and that for predicting TVB-N content of the slave variety are $0.65<\mathrm{R}_{\mathrm{p}}{ }^{2}=0.6992$ and $1.5<\mathrm{RPD}=1.58<2.0$.

According to the assessment foundation of model performance, we have obtained the following conclusions. The master variety PLSR model for predicting the water content of cold fresh pork is good for the master variety samples, although it is unworkable for the slave variety samples. The master variety PLSR model for 
predicting the $\mathrm{pH}$ value of cold fresh pork can be used in approximate quantitative calculation for the master variety samples, but it is unworkable for the slave variety samples. The master variety PLSR model for predicting the TVB-N content of cold fresh pork is good for the master variety samples, but it can only be used to assess the high or low values of the slave variety samples. Therefore, the master variety models for predicting the water content, $\mathrm{pH}$ value, TVB-N content of cold fresh pork should be maintained before they were used to predict the corresponding values of the slave variety samples.

\subsection{Model Updating Results of the PLSR Model of Water Content}

Table 2 shows the cross-validation results and the prediction results for the test set of the slave variety which were obtained by using the updating models of water content established by adding different numbers of representative slave variety (Enshi mountain pork ) samples to the calibration set of the master variety (N0.0 indigenous pork).

Table 2. The results of the water content models updated by adding different numbers of slave variety samples

\begin{tabular}{|c|c|c|c|c|c|c|c|}
\hline \multirow{2}{*}{$\begin{array}{c}\text { Number of } \\
\text { samples } \\
\text { added }\end{array}$} & \multirow{2}{*}{$\begin{array}{c}\text { number of } \\
\text { principal } \\
\text { components }\end{array}$} & \multicolumn{3}{|c|}{ Calibration set } & \multicolumn{3}{|c|}{ Test set of the slave variety } \\
\hline & & $\mathrm{R}_{\mathrm{cv}}^{2}$ & $\underset{1 \%}{\text { RMSECV }}$ & RPD & $\mathrm{R}_{\mathrm{p}}^{2}$ & $\begin{array}{c}\text { RMSEP } \\
1 \%\end{array}$ & RPD \\
\hline 0 & 13 & 0.9593 & 0.2091 & 4.99 & 0.2678 & 1.0300 & 0.87 \\
\hline 1 & 10 & 0.8720 & 0.4062 & 2.81 & 0.6895 & 0.7241 & 1.23 \\
\hline 2 & 10 & 0.8943 & 0.3725 & 3.08 & 0.7004 & 0.7276 & 1.23 \\
\hline 3 & 14 & 0.8787 & 0.4124 & 2.88 & 0.8019 & 0.6348 & 1.41 \\
\hline 4 & 14 & 0.8717 & 0.4194 & 2.80 & 0.8064 & 0.6480 & 1.38 \\
\hline 5 & 14 & 0.8921 & 0.3836 & 3.05 & 0.8128 & 0.6435 & 1.39 \\
\hline 6 & 15 & 0.9041 & 0.3701 & 3.23 & 0.8233 & 0.6418 & 1.39 \\
\hline 7 & 15 & 0.9062 & 0.3673 & 3.26 & 0.8156 & 0.6504 & 1.37 \\
\hline 8 & 14 & 0.8758 & 0.4184 & 2.85 & 0.8266 & 0.5576 & 1.60 \\
\hline 9 & 14 & 0.8539 & 0.4504 & 2.63 & 0.8163 & 0.5345 & 1.67 \\
\hline 10 & 14 & 0.8671 & 0.4393 & 2.76 & 0.8175 & 0.4791 & 1.87 \\
\hline 11 & 15 & 0.8741 & 0.4290 & 2.83 & 0.8224 & 0.4613 & 1.94 \\
\hline 12 & 15 & 0.8833 & 0.4147 & 2.94 & 0.8098 & 0.4723 & 1.89 \\
\hline 13 & 14 & 0.8848 & 0.4096 & 2.96 & 0.8104 & 0.4808 & 1.86 \\
\hline 15 & 14 & 0.8921 & 0.3958 & 3.06 & 0.8079 & 0.4837 & 1.85 \\
\hline 20 & 13 & 0.8964 & 0.3867 & 3.12 & 0.8167 & 0.4821 & 1.85 \\
\hline
\end{tabular}

We can conclude from Table 2 that after adding 11 slave variety Enshi mountain pork samples to the master variety No.0 indigenous pork samples, the performance of updating model for predicting water content of cold fresh pork tends to stabilize, and the prediction performance of the updated water content model for slave variety samples are $0.81<\mathrm{R}_{\mathrm{p}}{ }^{2}=0.8224<0.90$, and $1.5<\mathrm{RPD}=1.94<2.0$. According to the assessment foundation of model performance, we can conclude that the PLSR updating model for predicting water content can be used to identify the high or low 
values to be measured in the slave variety samples. In addition, the prediction results of the water content PLSR updating model for the master variety could be calculated and that are $0.81<\mathrm{R}_{\mathrm{p}}{ }^{2}=0.8179<0.90$, and $2.0<\mathrm{RPD}=2.1<2.5$. Obviously, the updating model can be used for approximate quantitative calculation of water content of the master variety samples.

Moreover, we can draw from Tables 1 and 2 the following conclusions. The model updating method caused limited improvement of the prediction precision of the water content PLSR model for the slave variety samples, and it only improves the model from being useless to being able to identify the high or low values of the slave variety samples. However, this updating model significantly influenced the prediction precision of the master variety samples and can reduce it from excellent prediction performance to approximate quantitative calculation. Therefore, the model updating method cannot be used to maintain the water content model of cold fresh pork.

\subsection{Model Updating Results of the PLSR Model of pH Value}

Table 3 shows the cross-validation results and the prediction results for the test set of the slave variety which were obtained by using the updating models of $\mathrm{pH}$ value established by adding different numbers of representative slave variety (Enshi mountain pork ) samples to the calibration set of the master variety (N0.0 indigenous pork).

Table 3. The results of the $\mathrm{pH}$ value models updated by adding different numbers of slave variety samples

\begin{tabular}{cccccccc}
\hline \multirow{2}{*}{$\begin{array}{c}\text { Number of } \\
\text { samples } \\
\text { added }\end{array}$} & $\begin{array}{c}\text { number of } \\
\text { principal } \\
\text { components }\end{array}$ & $\mathrm{R}_{\mathrm{cv}}{ }^{2}$ & $\begin{array}{c}\text { RMSECV } \\
\text { /\% }\end{array}$ & RPD & $\mathrm{R}_{\mathrm{p}}{ }^{2}$ & $\begin{array}{c}\text { RMSEP } \\
\text { /\% }\end{array}$ & RPD \\
\hline 0 & 19 & 0.8726 & 0.0817 & 2.80 & 0.3492 & 0.1509 & 0.86 \\
1 & 8 & 0.8601 & 0.0932 & 2.70 & 0.3201 & 0.1704 & 0.76 \\
2 & 6 & 0.8618 & 0.0930 & 2.71 & 0.3188 & 0.1601 & 0.81 \\
3 & 8 & 0.8788 & 0.0885 & 2.90 & 0.3057 & 0.1619 & 0.80 \\
4 & 10 & 0.8747 & 0.0896 & 2.84 & 0.3182 & 0.1612 & 0.81 \\
5 & 10 & 0.8854 & 0.0863 & 2.97 & 0.3248 & 0.1587 & 0.82 \\
10 & 4 & 0.7972 & 0.1166 & 2.19 & 0.3332 & 0.1472 & 0.88 \\
15 & 20 & 0.6690 & 0.1575 & 1.61 & 0.3461 & 0.1237 & 1.05 \\
20 & 2 & 0.6295 & 0.1603 & 1.56 & 0.4390 & 0.1222 & 1.07 \\
25 & 2 & 0.6877 & 0.1428 & 1.73 & 0.4635 & 0.1253 & 1.04 \\
30 & 2 & 0.6953 & 0.1383 & 1.76 & 0.4507 & 0.1278 & 1.02 \\
35 & 2 & 0.7085 & 0.1340 & 1.82 & 0.4996 & 0.1223 & 1.06 \\
40 & 4 & 0.7172 & 0.1318 & 1.81 & 0.5579 & 0.1119 & 1.16 \\
45 & 4 & 0.6530 & 0.1455 & 1.61 & 0.6160 & 0.0971 & 1.34 \\
\hline
\end{tabular}

We can conclude from Table 3 that although 45 slave variety (Enshi mountain pork) samples were added into the calibration set of the master variety (No.0 indigenous pork), the updating model for predicting $\mathrm{pH}$ value of cold fresh pork remains unworkable to the slave variety samples. The prediction performances of the $\mathrm{pH}$ value updating model for the slave variety samples are $R_{p}{ }^{2}=0.6160<0.65$ and 
$\mathrm{RPD}=1.34<1.5$. Therefore, the model updating method cannot be used to maintain the PLSR model for predicting $\mathrm{pH}$ value of cold fresh pork.

\subsection{Model Updating Results of the PLSR Model of TVB-N Content}

Table 4 shows the cross-validation results and the prediction results for the test set of the slave variety which were obtained by using the updating models of TVB-N content established by adding different numbers of representative slave variety (Jiajiakang pork) samples to the calibration set of the master variety (Enshi mountain pork).

Table 4. The results of TVB-N content models updated by adding different numbers of slave variety samples

\begin{tabular}{|c|c|c|c|c|c|c|c|}
\hline \multirow{2}{*}{$\begin{array}{c}\text { Number of } \\
\text { samples } \\
\text { added }\end{array}$} & \multirow{2}{*}{$\begin{array}{l}\text { number of } \\
\text { principal } \\
\text { camnonants }\end{array}$} & \multicolumn{3}{|c|}{ Calibration set } & \multicolumn{3}{|c|}{ Test set of the slave variety } \\
\hline & & $\mathrm{R}_{\mathrm{cv}}^{2}$ & RMSECV & $\mathrm{RPD}_{\mathrm{cv}}$ & $\mathrm{R}_{\mathrm{p}}{ }^{2}$ & RMSEP & $\mathrm{RPD}_{\mathrm{p}}$ \\
\hline 0 & 18 & 0.9706 & 1.1324 & 5.88 & 0.6992 & 3.0513 & 1.58 \\
\hline 1 & 18 & 0.9711 & 1.1307 & 5.92 & 0.6996 & 3.0829 & 1.56 \\
\hline 2 & 20 & 0.9483 & 1.5275 & 4.39 & 0.8568 & 2.1850 & 2.21 \\
\hline 3 & 20 & 0.9519 & 1.4591 & 4.57 & 0.8524 & 2.2040 & 2.19 \\
\hline 4 & 20 & 0.9468 & 1.5371 & 4.32 & 0.8836 & 1.9905 & 2.42 \\
\hline 5 & 20 & 0.9485 & 1.5174 & 4.38 & 0.8730 & 2.0111 & 2.40 \\
\hline 6 & 20 & 0.9425 & 1.6041 & 4.13 & 0.9038 & 1.7460 & 2.76 \\
\hline 7 & 20 & 0.9430 & 1.5873 & 4.15 & 0.8973 & 1.7626 & 2.74 \\
\hline 8 & 20 & 0.9444 & 1.5609 & 4.20 & 0.9049 & 1.6073 & 3.00 \\
\hline 9 & 20 & 0.9446 & 1.5647 & 4.22 & 0.9073 & 1.5837 & 3.04 \\
\hline 10 & 19 & 0.9076 & 2.0479 & 3.22 & 0.8901 & 1.8123 & 2.66 \\
\hline
\end{tabular}

We can conclude from table 4 that after adding 9 slave variety (Jiajiakang pork) samples to the calibration set of the master variety (Enshi mountain pork), the performance of the updating model for predicting TVB-N content of cold fresh pork tends to stabilize, and the prediction performance of the updated TVB-N content model for slave variety samples are $\mathrm{R}_{\mathrm{p}}{ }^{2}=0.9073>0.90$ and $\mathrm{RPD}=3.04>3.0$. According to the assessment foundation of model performance, we can obviously conclude that the prediction performance of the updating model for predicting TVB-N content of the slave variety samples is excellent. In addition, the prediction results of the TVB-N content PLSR updating model for the master variety could be calculated and that are $\mathrm{R}_{\mathrm{p}}{ }^{2}=0.9655>0.90, \mathrm{RPD}=5.40>3.0$. Obviously, the updating model is excellent for the master variety samples too. We can draw from Tables 1 and 4 the following conclusions. The model updating method significantly improved the prediction precision of the PLSR model of TVB-N content for the slave variety samples, and it improved the performance of the model for the slave variety samples from being able to identify the high or low values to being excellent. Furthermore, the updating model slightly affected the prediction precision for the master variety samples, and it is still excellent for the master variety samples. Therefore, the model updating method can maintain the TVB-N content model of cold fresh pork well. 


\section{Conclusions}

A survey was conducted to study the applicability of the model updating method to maintain the different index models of cold fresh pork. Maintaining the PLSR models for predicting water content, $\mathrm{pH}$ value, and TVB-N content of cold fresh pork by using model updating method, and we obtained the following conclusions.

1) The master variety model of water content of cold fresh pork shows a good prediction performance for the master variety samples $\left(R_{\mathrm{p}}{ }^{2}=0.9301>0.90\right.$, $\mathrm{RPD}=3.53>3.0)$ but it is unworkable for the slave variety samples $\left(\mathrm{R}_{\mathrm{p}}{ }^{2}=0.2687>0.50\right.$, $\mathrm{RPD}=0.87<1.5$ ). After adding 11 representative slave variety samples to the master variety calibration set, the performance of the updating model for predicting the water content of cold fresh pork is that the updating model can identify the high or low values of water content of the slave variety samples $\left(\mathrm{R}_{\mathrm{p}}{ }^{2}=0.8224>0.81\right.$, $\mathrm{RPD}=1.94>1.5$ ), and it can perform approximate quantitative analysis for the master variety samples $\left(\mathrm{R}_{\mathrm{p}}{ }^{2}=0.8179>0.81, \mathrm{RPD}=2.1>2.0\right)$. The results indicated that model updating method caused limited improvement for the prediction precision of the water content PLSR model for the slave variety samples, and it only improves the model from being useless to being able to identify the high or low values of the slave variety samples. However, this updating model significantly influenced the prediction precision of the master variety samples and can reduce it from excellent prediction performance to approximate quantitative calculation. Therefore, the model updating method cannot be used to maintain the water content model of cold fresh pork.

2) Although 45 slave variety (Enshi mountain pork) samples were added into the calibration set of the master variety (No.0 indigenous pork), the updating model for predicting $\mathrm{pH}$ value of cold fresh pork remains unworkable to the slave variety samples. The prediction performances of the $\mathrm{pH}$ value updating model for the slave variety samples are $\mathrm{R}_{\mathrm{p}}{ }^{2}=0.6160<0.65$ and $\mathrm{RPD}=1.34<1.5$. Therefore, the model updating method cannot be used to maintain the PLSR model for predicting $\mathrm{pH}$ value of cold fresh pork.

3) Before using the model updating method, the master variety PLSR model for predicting TVB-N content shows a good prediction performance to the master variety samples $\left(\mathrm{R}_{\mathrm{p}}{ }^{2}=0.9503>0.90\right.$, and $\left.\mathrm{RPD}=4.25<3.0\right)$, but it shows a worse prediction performance to the slave variety samples and it only can identify the high or low values of TVB-N content $\left(0.65<\mathrm{R}_{\mathrm{p}}{ }^{2}=0.6992<0.81,1.5<\mathrm{RPD}=1.58<2.0\right)$. The updating model was built by adding 9 representative slave variety samples to the master variety calibration set, and its prediction performance was good for both the master and slave variety samples (the prediction results for the master variety was $R_{p}{ }^{2}=0.9655>0.90$ and $\mathrm{RPD}=5.40 .3>3.0$, the prediction results for the salve variety was $\mathrm{R}_{\mathrm{p}}{ }^{2}=0.9073>0.90$ and $\mathrm{RPD}=3.04>3.0$ ). The results indicated that the model updating method can well maintain the TVB-N content model of cold fresh pork.

4) By using model updating method, the maintenance results for the PLSR hyperspectral model of water content, $\mathrm{pH}$ value and TVB-N content of cold fresh pork vary greatly. The method can well maintain the TVB-N content model, but the maintenance result for the water content model is slightly worse, furthermore it cannot maintain the $\mathrm{pH}$ value model. The results indicated that the applicability of the model updating method varies in different detection index models for cold fresh pork. The model updating method can well maintain the hyperspcetral model of TVB-N 
content of cold fresh pork, but it cannot maintain the hyperspectral models of water content and $\mathrm{pH}$ value of cold fresh pork.

\section{Acknowledgment}

Fund for this research was provided by the project 2662015QC024 supported by the Fundamental Research funds for the Central Universities.

\section{References}

1. Chu X.L., Yuan H.F., Lu W.Z.:Model transfer in multivariate calibration.J. Spectroscopy and Spectral Analysis. 21 (6):881- 885(2001)

2. Yan Y.L. :Near infrared spectroscopy analysis foundation and application.M. Beijing: China Light Industry Press (2005).

3. Zhang X.B., Feng Y.C., Hu C.Q.:Progress in calibration transfer of near-infrared multivariate model.J. Journal of Pharmaceutical Analysis 29(8): 1390-1399(2009)

4. Chu X.L., Yuan H.F., Wang Y.B., et al: Developing robust near infrared calibration models.J. Spectroscopy and Spectral Analysis, 24(6):666-671(2004)

5. Xie L.J., Ying Y.B.:Priliminary research on calibration model maintenance method for transgenic tomato discriminant.J.Journal of Jiangsu University,33(5): 538-542 (2012)

6. Candolfi A, Massart D.L.:Model updating for the identification of NIR spectra from a pharmaceutical excipient.J.Applied Spectroscopy, 54(1):48-53(2000)

7. Zou W.B., Feng Y.C., Hu C.Q.: Update of near-infrared models for testing ceftazidime, water and arginine in ceftazidime for injection.J. Spectroscopy and Spectral Analysis, 34(10). 2617-2622(2014)

8. Zhao Z, Li X.Y., L.J., et al.:Correction methods of pork total volatile basic nitrogen content detection model based on hyperspectral imaging technology.J.Journal of Food Safety and Quality. 4(3):883-889 (2013)

9. Zhong X.B.,:Maintenance methods of quality detection model for different varieties of pork based on hyperspectral imaging technology.D.Wuhan:Huazhong Agricultural University (2014)

10. Jin Y., Ding H.Y., Wu Y.J., et al.:Near-infrared spectroscopy online and realtime monitoring of extraction process of Xuebijing Injection.J.Chin J Pharm Anal, 12141221(2012)

11. Zou W.B.:Construction and updating of universal quantitative models for testing azithromycin by near-infrared diffuse reflectance spectroscopy. Crystalline water of ranolazine hydrochloride and the influence on its crystallization.D. Beijing:Peking Union Medical College(2012)

12. Candolfi A., Massart D L.: Model Updating For The Identification Of Nir Spectra From A Pharmaceutical Excipient.J. Applied Spectroscopy, 54(1):48-53(2000)

13. Xu B., Wu Z., Lin Z., et al. NIR analysis for batch process of ethanol precipitation coupled with a new calibration model updating strategy.J. Analytica Chimica Acta, 720:2228(2012)

14. Kramer K.E., Small G.W. :Digital filtering and model updating methods for improving the 
robustness of near-infrared multivariate calibrations.J. Applied Spectroscopy, 63(2):246255(10) (2009)

15. Yao S., Wu G.F, Jiang Y.F, et al.:Extending hemicelluloses content calibration of Acacia spp using NIR to new sites.J.Spectroscopy and Spectral Analysis,30(5): 1206-1209 (2010)

16. Fu Q.B., Suo H., He X.P., et al.:Transfer calibration for alcohol determination using temperature-induced shortwave near infrared spectra.J.Spectroscopy and Spectral Analysis, 32(8):2080-2084 (2012)

17. GB 5009.3-2010 The national food safety standard of the People's Republic of China, determination of moisture in foods. (2010)

18. NY/T 821-2004 The standard of Agriculture Ministry of the People's Republic of China,Technical regulation for determination of pork quality(2004)

19. GB/T 5009.44-2003 The national standard of the People's Republic of China, Method for analysis of hygienic standard of meat and meat products (2003)

20. Zhan X.R., Zhu X.R., Shi X.Y., et al.:Determination of hesperidin in tangerine leaf by near-infrared spectroscopy with SPXY algorithm for sample subset partitioning and Monte Carlo cross validation .J. Spectroscopy and Spectral Analysis,229(4):964-968. (2009)

21. Yang H.Q. :Modelling and instrumentation of soil and plant selected properties ba sed on visible-near-infrared spectroscopy.D. Hangzhou: Zhejiang University (2012)

22. Cao D.S., Liang Y.Z., Xu Q.S., et al.:A new strategy of outlier detection for QSAR/QSPR.J. Journal of Computational Chemistry, 31(3):592 602(2010)

23. Zhou Z.Methodology for nondestructive detection of potato quality based on hyperspectral image technology.D. Wuhan: Huazhong Agricultural University(2012) 